\title{
Malinche: diálogos entre culturas
}

\author{
Malinche: diálogos entre culturas
}

\section{Maria Luana dos Santos \\ Alexandra Santos Pinheiro}

Universidade Federal da Grande Dourados - UFGD - Dourados - Mato Grosso do Sul - Brasil

Resumo: Analisamos a obra Malinche (2006), de Laura Esquivel, destacando o diálogo intercultural que pode ser estabelecido entre as duas culturas que estiveram justapostas no período de colonização da América Espanhola, sem deixar de considerar o potencial transformador de produções literárias. Destacamos a influência da língua no desenvolvimento do contato cultural e, também, a sua incidência no desdobramento de narrativas e contra-narrativas no espaço da hibridização cultural do solo mexicano. Após estas divagações, tentamos assinalar a influência que o diálogo cultural exerce na constituição identitária do povo mexicano, bem como, latinoamericano. Essa perspectiva de investigação acabou por reverberar em uma certeza: a existência de um discurso da/para a América Latina.

Palavras-chave: Interculturalidade latino-americana. Literatura mexicana. Constituição identitária

Resumen: Analizamos la obra Malinche (2006), de Laura Esquivel, poniendo énfasis en el diálogo intercultural que puede ser establecido entre las dos culturas que estuvieron yuxtapuestas al período de la colonización de América Española, sin olvidar el potencial trasformador de las producciones literarias. Destacamos la influencia de la lengua en desarrollo del contacto cultural y, todavía, su incidencia en el desdoblamiento de narrativas y contra narrativas, en el espacio mismo de la hibridación cultural de la tierra mexicana. Pasado estas divagaciones, intentamos señalar el influjo que el dialogo cultural ejerce en la constitución identitária del pueblo mexicano, bien como, latinoamericano. Esa perspectiva de análisis reverberó en una certeza: la existencia de un discurso de la/para la América Latina.

Palabras-clave: Interculturalidad latinoamericana. Literatura mexicana. Constitución de la identidad. 


\section{Considerações iniciais}

¿Por qué persistes, incesante espejo?/¿Por qué duplicas, misterioso hermano,/el movimiento de mi mano?/¿Por qué en la sombra el súbito reflejo?/Eres el otro yo de que habla el griego/y acechas desde siempre. En la tersura/del agua incierta o del cristal que dura/me buscas y es inútil estar ciego. /El hecho de no verte y de saberte/te agrega horror, cosa de magia que osas/multiplicar la cifra de las cosas/que somos y que abarcan nuestra suerte. /Cuando esté muerto, copiarás a otro/y luego a otro, a otro, a otro, a otro... Jorge Luis Borges

É assim que se cria uma história única, mostre um povo como uma coisa, como uma única coisa, vezes sem conta, e é isso que ele se torna.

Chimamanda Adichie

Como um jogo de espelho que não permite ver o eu como realmente é, mas apenas simulacro, analisamos a obra Malinche (2006), da escritora mexicana Laura Esquivel, que possibilita a reflexão sobre a região da América Central, correspondente ao México.

O texto em questão narra, ficcionalísticamente, um recorte do século XVI, envolvendo as concepções teóricas inerentes ao pensamento crítico-

reflexivo das últimas décadas. Destarte, podemos observar o contato estabelecido entre os representantes da coroa espanhola, bem como, das civilizações astecas. Ganham "vida" na obra de Esquivel: Hernan Cortés ${ }^{1}$, Malinche ${ }^{2}$ e Montezuma ${ }^{3}$, ambos em uma relação dialógica, na qual se sobressaem relações de poder/domínio. O que se percebe, inquestionavelmente, é o diálogo entre culturas, as relações passíveis de serem estabelecidas entre outridades, que não são semelhantes, porém complementares. Tais relações estão presentes na produção em foco, mas podem ser tomadas como meio para a reflexão de padrões socioculturais "já consolidados".

Tentamos demonstrar que por meio do diálogo cultural, ou da interculturalidade, tanto no nível textual quanto sociohistórico e cultural, é factível a língua atuar como mediadora das relações interculturais, assim como incidir diretamente na transformação de

\footnotetext{
${ }^{1}$ Conquistador espanhol.

2 Escrava asteca adjetivada de distintas maneiras, ora tradutora, ora amante do colonizador, ora maldição das civilizações pré-colombianas.

3 Um dos muitos imperadores astecas. Esse, especificamente, controlava a região no período de que trata a obra [e, que remete ao período histórico que assinala].

${ }^{4}$ Pensemos o processo de constituição latino-americano, assim como, a formação do discurso local que se tem elaborado nos últimos tempos na/pela América Latina.
}

espaços mediados. Ademais, de atuar não apenas nos domínios da tradução linguística, mas prioritariamente na tradução cultural, já que a personagem que dá título à obra, e é a tradutora, não atua somente no campo linguístico possibilitando que as partes entrem em contato com aspectos culturais umas das outras.

Procuramos demonstrar, ainda, que a língua é um meio de poder capaz de desenvolver narrativas e contra-narrativas, sendo que, narrativas tendem a perpetuar o jogo da unicidade das sociedades, com a manutenção de histórias únicas. $\mathrm{E}$, as contranarrativas, ao contrário, enfatizam a heterogeneidade dos povos, além de proporcionar a reflexão sobre a natureza híbrida dos povos latino-americanos.

Nas malhas do diálogo intercultural, percebese a construção de narrativas outras, isto é, de narrativas que não exaltam essa ou aquela história, mas que destacam o entremeio de ambas. Esses espaços liminares são referidos nos seguintes termos por Palermo:

Los espacios liminares así construidos, [...] están marcados por el desdibujamiento de los límites entre lo real y lo imaginario, entre mundo y representación, [...]. Por ello construyen un lugar nuevo, un tercer lugar indeterminado, en el que también se diluye el consuetudinario esquema de poder y, por eso mismo, donde las identidades se encuentran en procesos de reconfiguración.

Este "tercer lugar", entonces, constituye [...] un campo de fuerzas en el que se actualizan las contradicciones, en el que la lucha por la hegemonía se traduce en el diseño de unos lindes simbólicos, linguísticos, subjetivos, representacionales "otros" [...]. Se trata de un espacio elusivo en el que conocer el mundo ya no significa su apropiación porque todas las reglas inventadas para ellos han caído en la vacuidad e inoperancia; es ese espacio "de la espera" en el que ya lo que era no es y en el que todo está por ser construido (PALERMO, 2004, p. 242).

Em síntese, configura-se o espaço onde ocorre o desenvolvimento de uma narrativa que dá conta dos matizes característicos da constituição da sociedade mexicana, assim como da América Latina. Lugar marcado pela interculturalidade, e que possui a capacidade de promover o desenvolvimento de uma narrativa própria, centrada nas cores e aromas locais ${ }^{5}$.

\footnotetext{
5 Vale ressaltar, então, que a partir da análise empreendida toma-se o texto literário segundo padrões verossímeis. Assim, a literatura acabaria por adotar características inerentes à metaficção historiográfica nos moldes propostos por Linda Hutcheon (1991), bem como, ultrapassaria os limites do deleite esperado para os textos literários, adotando uma constituição crítica, capaz de auxiliar no processo de transformação social e ideológica daqueles que a eles se acercam.
} 


\section{0 código oral: mediação e transformação}

Nas sendas da interculturalidade, dois conceitos/espaços incorporam um jogo dialético característico, marcado pelo ato da mediação, e que inclui uma tarefa que está em sua essência: promover transformações nos polos mediados. Na obra em discussão, a mediação se dá, sobretudo, pela manipulação do código oral, pois é por meio da dominação da língua, dentro de sua perspectiva de estabelecimento de contato entre partes, que relações nos mais variados campos tomam forma. É pela língua que alianças são efetivadas, o poder de dominação é ampliado e o diálogo entre culturas constituído. Não é difícil compreender a amplitude do espaço ocupado pela língua, quando:

Ao longo da vida, à medida que amadurecia, comprovava que não havia melhor arma do que um bom discurso. No entanto, agora se sentia vulnerável e inútil, desarmado. Como poderia utilizar a sua melhor e mais eficiente arma diante daqueles nativos que falavam outras línguas? [...] Ele sabia que não Ihe bastariam os cavalos, a artilharia $e$ os arcabuzes para conseguir o domínio daquelas terras (ESQUIVEL, 2007, p. 40).

Assim, a língua é entendida como um mecanismo de poder muito importante para Cortés, principalmente quando este toma ciência de que não poderá fazer uso de sua característica mais fundamental. O conquistador espanhol se apercebe da falta de domínio do código local e reconhece que este é um ponto deficiente para sua ambição, já que o contato entre as partes não se dá de modo satisfatório e o processo de dominação não se consolida plenamente.

O poder retorna para Cortés por meio do domínio das línguas que é representado pelo "controle" da escrava Malinche. Uma manipulação parcial, pois a personagem aprende rapidamente com o colonizador "a sensação gerada por estar no comando. Logo aprendeu: quem controla a informação, os significados, adquire poder. Ao traduzir, dominava a situação, e não apenas isso: a palavra podia ser uma arma. A melhor das armas" (ibidem, p. 70). Ou seja, a escrava asteca, mais que o seu próprio dono, é quem possui de fato o controle da língua, é através dela que se dá a mediação entre as partes e o processo de transformação toma molde.

Tal personagem passa a ocupar papel importante para a conquista asteca, bem como, na efetivação de um cenário cultural diferenciado, marcado pelo diálogo entre culturas. Culturas que, ao mesmo tempo em que adota particularidades de cultura outra, apropria-se e transforma-a de acordo com seus próprios padrões culturais. É possível pensar, também, que a tradução linguística interfere na tradução cultural. Tomemos, então:

Aguilar só fala a língua dos maias ${ }^{6}$, que não é a dos astecas. A segunda personagem essencial dessa conquista de informação é uma mulher [...] 'la Malinche'. Ela é dada de presente aos espanhóis, durante um dos primeiros encontros. Sua língua materna é o nahuatl, a língua dos astecas; mas foi vendida como escrava aos maias, e também dominava a língua deles. Há, pois, no início, uma cadeia bastante longa: Cortés fala a Aguilar, que traduz o que ele diz para a Malinche, que por sua vez se dirige ao interlocutor asteca. Seus dons para as línguas são evidentes, e em pouco tempo ela aprende o espanhol, o que aumenta sua utilidade (TODOROV, 2003, p. 144).

As dificuldades de tradução são também direcionadas na obra ficcional, tendo em vista que se iniciam os conflitos inerentes a prática da tradução. Logo após dominar o espanhol, mais que traduzir palavras, era preciso que as traduções despertassem significados para ambas as partes, aqueles que dominavam o nahuatl e os que tinham o espanhol por língua materna. Contudo, quando se aborda a construção da significação está-se traduzindo culturas e a si mesmo, e como isso é possível no contexto que se desenhava? A tradutora, diante de sua função e importância, entra em conflito:

Ser a 'língua' era uma enorme responsabilidade. Não queria errar, não queria se equivocar e não via como evitar, pois era difícil traduzir, de uma língua para outra, conceitos complicados. Ela sentia que, cada vez que alguém pronunciava uma palavra, viajava na memória de centenas de gerações. Quando alguém nomeava Ometeotl, o criador

\footnotetext{
${ }^{6}$ A língua dos maias recebe a mesma denominação da "etnia".
} 
da dualidade Ometecihtli-Omecihuatl, o princípio masculino e feminino, instalava-se no momento mesmo da criação. Esse era o poder da palavra falada. Então, como encerrar numa única palavra, Omeoteotl, aquele que não tem forma, o senhor que não nasce e não morre, a quem a água não pode molhar, o fogo não pode queimar, o vento não pode mover do lugar e a terra não pode cobrir? Impossível (Op. cit., p.66-67).

Nesse sentido, Malinche torna clara não somente a dificuldade de realizar a tradução entre línguas, mas, principalmente, a tradução cultural. Como traduzir a cultura asteca para o patamar da inteligibilidade/compreensão

espanhola?

Principalmente, porque os padrões culturais eram completamente distantes à época da colonização. Os signos, bem como os contextos de produção de sentido acabariam por influenciar na forma como a cultura de uns era recebida por outros, e vice-versa. A respeito das perspectivas de tradução, vislumbramos que:

[...] o significado não se encontra para sempre depositado no texto, à espera de que um leitor adequado o decifre de maneira correta. O significado de um texto somente se delineia, e se cria, a partir de um ato de interpretação, sempre provisória e temporariamente, com base na ideologia, nos padrões estéticos, éticos e morais, nas circunstâncias históricas e na psicologia que constituem a comunidade sociocultural - a 'comunidade interpretativa', no sentido de Stanley Fish - em que é lido. O que vemos num texto é exatamente o que nossa 'comunidade interpretativa' nos permite ler naquilo que lemos, mesmo que tenhamos como único objetivo o resgate dos seus significados supostamente 'originais', mesmo que tenhamos como único objetivo não nos misturarmos ao que lemos. Do mesmo modo que não podemos deixar de lado o que somos e o que pensamos quando nos relacionamos com o mundo real, também não podemos ler um texto sem que projetemos nessa leitura as circunstâncias e os padrões que nos constituem enquanto leitores e membros de uma determinada comunidade (ARROJO, 1993, p. 19).

Logo, não existe a possibilidade de uma tradução ser isenta das impressões de quem realiza a tradução, assim como é impossível essa tradução ser recebida da maneira como foi concebida, pois o contexto em que tal tradução ocorre e é recepcionada, é permeado pelos padrões e matizes 'locais', inerentes ao grupo a que pertence o sujeito. A raiz das dificuldades de Malinche, enquanto tradutora, encontra-se nesse ponto, isto é, ser fiel ao texto, aos seus próprios desejos ou, às prioridades/anseios de quem recebe a tradução.

A questão que se apresenta quando culturas colocam-se face to face é deparar com o outro, aquele que se visualiza a sua frente, é lidar com as fronteiras abstratas, mas altamente palpáveis que se estruturam. A fronteira não como a linha divisória $(\text { limite })^{7}$, mas como espaço da comunicação, do diálogo entre culturas. É nesse espaço de conversa cultural, discussão, às vezes, que identidades particulares/ímpares se formam.

A fronteira, marcada pela interculturalidade, incidirá diretamente na (re)elaboração da identidade do povo asteca, bem como dos espanhóis em novo solo. Desse diálogo fronteiriço resultará a "nova raça" de que trata o narrador de Esquivel. Um povo marcado pela heterogeneidade de costumes, crença híbrida e mescla de genes, muitas vezes expostas nas reflexões e falas da protagonista. A esse respeito observemos ao excerto:

Que pode saber você de Deus? Seus deuses exigem todo o sangue do mundo para existir, em compensação, Deus nos entrega o dele em cada comunhão. Nós bebemos o seu sangue.

Malinalli não entendeu de todo as palavras de Cortés. O que ela queria escutar, e seu cérebro entender, era que o deus dos espanhóis era um deus líquido, pois no sangue, no segredo da carne, no segredo do amor, estava contida a eternidade do universo, e ela queria acreditar numa divindade assim (ESQUIVEL, 2007, p. 67-8).

Que evidencia o diálogo/contato cultural, por meio do estabelecimento das diferenças entre os deuses de Malinche, e o Deus de Cortés. O principal ponto, no entanto, não é a diferenciação daquilo que um deus quer ou não de seus seguidores, mas aquilo que Malinche quer entender acerca do Deus de Cortés. A representação a qual ela chega torna esse outro deus "bom", pois é o deus que ela deseja e que é significativo dentro dos padrões culturais e esquemas cerebrais que ela possui. Ou seja, a

7 Cf. CHAVES, Flávio Loureiro. "A fronteira da literatura". In: Ponta de estoque. Caxias do Sul, RS: Educs, 2006. 
interpretação que a nativa realiza da fala do estrangeiro é aquela que a sua "comunidade interpretativa" ${ }^{8}$ Ihe permite inferir.

Se este traço foi possível na tradição cultural asteca, também incidiu fortemente na tradição cultural espanhola que dialogava, mesmo por meio da negação, com a cultura desses povos. Nesse prisma, percebe-se a ressignificação de identidades, personalidades e poder, como se observa em:

Cortés, seria [sic] para sempre grata pelo filho e o marido que me deu, o pedaço de terra amavelmente concedido a Jaramillo e a mim para fincarmos raízes, mas não me peça, nesse tom, que deponha. Já não sou sua língua, senhor Malinche.

Havia muito ninguém o chamava de Malinche. Deixaram de chamá-lo assim quando Malinalli se casou com Jaramillo, quando deixou de ser sua mulher, quando se separaram. Cuspiu fogo pelos olhos e com fúria contida se dirigiu a ela:

Quem pensa que é para me falar assim? (ibidem, p. 183).

Com o passar do tempo e a intensificação do processo de hibridização ${ }^{9}$ cultural, as personalidades e poderes adquirem nova significação social. O poder não pertence mais a Cortés, e o título que antes era sinal de distinção, torna-se signo de depreciação, bem como de demonstração de força por Malinche. Esse fragmento coloca em destaque a força da cultura asteca e a representatividade da indígena no processo de conquista, ou seja, o grande dominador é reconhecido, antes, pela importância da intérprete perante os povos indígenas, do que pelo seu nome espanhol. A língua assume, nesse momento, papel preponderante, pois há a hipótese dessa designação para Cortés ocorrer devido à dificuldade que os indígenas possuíam em pronunciar a letra " $r$ " do idioma espanhol.

É o código oral que desempenha toda a articulação nas relações que são estabelecidas entre os povos, atuando na consolidação da dominação

\footnotetext{
8 A comunidade interpretativa advem do meio em que a personagem está inserida e dos padrões político-sócio-culturais que interferem nos valores de um grupo. A concepção de comunidades imaginadas proposta por Benedict Anderson.

9 Cf. COSER, Stelamaris. "Híbrido, hibridismo e hibridização". In: Conceitos de Literatura e cultura. (Eurídice Figueiredo, organizadora). Juiz de Fora: UFJF, 2005. p. 163-188., que enfoca em profundidade o conceito.
}

espanhola, assim como no contato cultural entre as civilizações. A língua foi a força motriz durante a versão da colonização de Esquivel, pois ao passo que mediava, transformava padrões culturais e sociais na sociedade que começava a constituir-se, não sendo índia, tampouco espanhola.

\section{Culturas errantes: a contra-narrativa como metáfora}

As culturas são errantes. Elas não respeitam os limites "nacionais", convivem no espaço fronteiriço, adotam, assim, o nomadismo. Inevitavelmente, esta é uma prática que permite o diálogo entre povos e culturas, já que os limites e as fronteiras não ocupam espaço prioritário. O diálogo entre 'outros'/partes é estabelecido, e a construção de uma narrativa desse contexto é desencadeada. Uma narrativa imaginada, inicialmente, em condição homogênea, mas que resulta vigorosamente heterogênea.

Quando da colonização, em situação contrária às culturas errantes, buscou-se consolidar o discurso da univocidade, no qual apenas uma história era narrada, um ponto de vista privilegiado, o 'outro' figurava como a representação de um único padrão, somente um deus e uma fé eram exaltados, bem como apenas uma língua foi convertida em oficial. A narrativa única buscava a anulação do outro enquanto sujeito, assim:

Evitar o bilingüismo significa evitar o pluralismo religioso e significa também impor - poder colonialista. $\mathrm{Na}$ álgebra do conquistador, a unidade é a única medida que conta. Um só Deus, um só Rei, uma só Língua: o verdadeiro Deus, o verdadeiro Rei, a verdadeira Língua. Como dizia recentemente Jaques Derrida: ' $O$ signo e o nome da divindade têm o mesmo tempo e o mesmo lugar de nascimento.' Uma pequena correção se impõe na última parte da frase, o suplemento de um prefixo que visa a atualizar a afirmativa '...o mesmo tempo e o mesmo lugar de renascimento' (SANTIAGO, 2000, p. 14).

Inicialmente, o que ocorre é a construção de uma narrativa que busca tornar os cidadãos astecas em sujeitos sociais dirigidos pelos padrões europeus, mais especificamente espanhóis. Em que o culto 
politeísta seria substituído pelo monoteísmo cristão, o imperador asteca daria lugar ao rei da Espanha e as diversas línguas locais (nahuatl, maia e quéchua, para exemplificar) seriam suplantadas pelo castelhano. O padrão seria aceito e disseminado, assim:

[Malinche] Encantara-se ao escutar no sermão prévio ao batismo - que o próprio Aguilar traduzira para todos - que os espanhóis pediam que não continuassem a se deixar enganar por deuses falsos que exigiam sacrifícios humanos. Que o deus verdadeiro que eles traziam era bom e amoroso e nunca exigiria algo desse tipo (ESQUIVEL, 2007, p. 51).

Os contornos locais, centrados nos sacrifícios humanos, de certo modo, acabavam por promover a aceitação de um Deus que se opunha aos sacrifícios humanos. Na realidade, a crença em vários deuses, também, facilitava a disseminação de um Deus, pois, nos matizes locais era encarado apenas como mais um deus. A ausência de questionamentos por parte de Malinche denuncia a aceitação complacente de padrões culturais alheios à cultura "local", assim como, a condescendência para com uma narrativa que colocava as civilizações nativas como inferiores e portadoras de padrões culturais equivocados. Uma mesma e antiga narrativa renascia, tornava-se 'nova' em outro solo.

No entanto, o diálogo cultural estabelecido entre as civilizações ameríndias e a espanhola não privilegiou uma ou outra cultura, ademais não seguiu a narrativa que era construída por valores exteriores/estrangeiros as características "típicas", "regionais". Ao contrário, houve a elaboração de contra-narrativas, que privilegiaram 0 desenvolvimento de narrativas no plural. Desse modo:

As contra-narrativas da nação que continuamente evocam e rasuram suas fronteiras totalizadoras - tanto reais quanto conceituais - perturbam aquelas manobras ideológicas através das quais 'comunidades imaginadas' recebem identidades essencialistas. Isto porque a unidade política da nação consiste em um deslocamento contínuo da ansiedade do espaço moderno irremediavelmente plural (BHABHA, 1995, p. 211).

Ou seja, a disseminação de uma narrativa única é combatida pela contra-narrativa do período em que a obra é escrita (século XXI). É desse período histórico, com todos os implicantes que interferem diretamente no padrão crítico-reflexivo dos sujeitos sociais, que se lança o olhar para o diálogo cultural estabelecido no século XVI. A narrativa única é combatida, também, pela apropriação que ocorre dos signos, símbolos disseminados, de modo diverso ao esperado pelo conquistador. Então, é evidente a construção de outra(s) narrativa(s) para o passado pontuado na obra. Narrativas onde:

A fronteira que assinala a individualidade da nação interrompe o tempo autogerador da produção nacional e desestabiliza 0 significado do povo como homogêneo. [...] Estamos diante da nação dividida no interior dela própria, articulando a heterogeneidade de sua população. [...] [A "nação"] torna-se um espaço liminar de significação, que é marcado internamente pelos discursos de minorias, pelas histórias heterogêneas de povos em disputa, por autoridades antagônicas e por locais tensos de diferença cultural (ibidem, $p$. 209-210).

A ideia de nação homogênea proposta pelo aparato de conquista espanhol, no início da obra, isto é, a narrativa única da história é questionada pela contra-narrativa dos momentos finais. A heterogeneidade é evidenciada por meio das representações proporcionadas pelo diálogo cultural e, do hibridismo, quando este último privilegia as particularidades culturais sem torná-las homogêneas e constituintes do projeto unificador do estado-nação.

A contra-narrativa, desenvolvida no texto de Esquivel, torna possível a visualização dos povos da recém-encontrada América, segundo a sua especificidade híbrida e transcultural ${ }^{10}$, ou seja, os astecas não são mais os mesmos de antes da chegada dos espanhóis, tampouco são o outro que se Ihes apresentou, mas um terceiro resultado. O meio

10 Sobre transculturação, cf. AGUIAR, Flávio \& VASCONCELOS, Sandra G. "O conceito de transculturação na obra de Ángel Rama. In: Margens da cultura: mestiçagem, hibridismo \& outras misturas. (Benjamin Abdala Júnior, organizador). São Paulo: Boitempo, 2004. p. 87-97. 
pelo qual o diálogo cultural é trazido à tona feito um retrato, onde não se borram as partes e a totalidade da cena é revelada. Essa é, também, a conclusão a que chega o narrador: "__ A vida sempre nos oferece duas possibilidades: o dia e a noite, a águia e a serpente, a construção e a destruição, [...] mas há sempre uma terceira possibilidade oculta unificando as duas: trate de descobri-la." (ESQUIVEL, 2007, p. 61).

É dessa terceira possibilidade que trata Malinche (2006), onde o diálogo cultural se torna uma alternativa. Espaço em que os sabores e sangues se misturam sem que haja o prejuízo das partes ${ }^{11}$, ou ainda, no âmbito em que dois tornam-se um, mas ao mesmo tempo seguem sendo os dois iniciais, pois reúne as características das duas partes. Importante, nesse caso, é alimentação, primeiro retrato do diálogo/harmonização entre culturas:

O coração se alegrava ao observar os novos rebentos de milho no milharal na parte traseira da casa. [...] Ao lado do milharal conviviam harmoniosamente plantas de origem européia e plantas mexicanas. Malinalli se comprazia em criar novos pratos. Divertia-se com cebola, alho, coentro, manjericão, salsa, tomate, nopais, romãs, bananas, mangas, laranjas, café, trigo, milho, cacau. Os novos sabores na comida surgiam sem resistência à mestiçagem. Os diferentes ingredientes se aceitavam sem problema, e o resultado era surpreendente (ibidem, p. 178-179).

Através da apropriação e hibridação dos alimentos, há a possibilidade de adentrar nos limites caros à interculturalidade. Quando o alimento é aceito como pertencente ao grupo, tem-se diante a dimensão exata do ponto em que as culturas se tocam, estabelecem trocas e junções culturais. Ademais da representatividade desempenhada pela

\footnotetext{
11 Quiçá soe estranha a ideia de que o contato entre partes "não traga prejuízos" para ambas, afinal sempre somos levados a pensar em prejuízo de uma maneira negativa, mas é importante lembrar que estamos lidando com uma obra que aborda especificamente um contato sociocultural transformador. Assim, quando associamos "sem prejuízo" à transformação proposta pela obra de Esquivel, podemos/devemos atribuir a essa expressão uma significação positiva, pois o contato promove a interculturalidade/hibridação característica que nós, latino-americanos, sabemos não ser negativa. Se agirmos/pensarmos de outro modo estaremos negando quem somos, colocando-nos em posição de vítimas do processo colonial, e, concordando com aqueles que insistem em nos dizer que somos inferiores.
}

associação de alimentos e sabores, a própria constituição dos sujeitos resultantes do diálogo cultural encena os pontos característicos da sociedade que se desenha. O resultado obtido no campo da culinária:

Era o mesmo resultado obtido no interior de seu ventre [de Malinche]. Seus filhos eram produtos de diferentes sangues, odores, aromas, cores. Assim como a terra dava milho azul, branco, vermelho e amarelo - mas permitia a mescla entre eles -, era possível a criação de uma nova raça sobre a terra. Uma raça que contivesse todas. Uma raça na qual se alegrasse aquele que dá a vida, com todos os seus diferentes nomes, com todas as suas diferentes formas. Essa era a raça de seus filhos (ibidem, idem).

O desenlace do diálogo/contato cultural são sujeitos heterogêneos, marcados pela união de todos os demais, nativos e estrangeiros. Tal assertiva permite transferir o detalhe a que se chega para 0 contexto mexicano atual, bem como para o latinoamericano. Ou seja, o cenário cultural latinoamericano é marcado pela interculturalidade, onde o diálogo cultural desenvolvido no passado leva à realidade contemporânea ${ }^{12}$.

Não se está negando a existência de conflitos, nem dentro da obra, muito menos no período que é retratado por esta. No entanto, é evidente que para Laura Esquivel, o mais importante nessa produção é demonstrar que esse período foi positivo para seu povo, mesmo com todos os massacres que foram cometidos no período e são de conhecimento da humanidade. Tal fato leva-nos a pensar que uma nação como o México de nossos dias, precisa olhar de maneira diferenciada para seu passado histórico, e talvez, seja esse o objetivo da escrita, proporcionar ao menos um gatilho para disparar esse processo de reflexão. Uma reflexão que os faça ver que a

\footnotetext{
12 Cf. AGAMBEM, Giorgio. O que é o contemporâneo? e outros ensaios. Chapecó: Editora Argos, 2009.
} 
"maldição de Malinche"13 não trata-se de uma grande maldição de fato.

A contra-narrativa [proposta e presente na obra] atua, assim, como desmistificadora da narrativa única que se buscou construir acerca dos povos précolombianos. Serve, também, de metáfora para os sujeitos sociais da América Latina, pois evidencia uma narrativa que é heterogênea, ao modo dos atores sociais dessa região do planeta. Além de tornar claro o quanto esses sujeitos são constituídos por culturas errantes/nômades, já que são trespassados por várias faixas de influências que incidem diretamente na constituição de suas identidades.

\section{Considerações finais}

Nos momentos finais de Malinche (2006), deparamos com a constituição de uma "nova raça" que é híbrida, um misto de europeu com indígena. Torna-se translúcida essa condição heterogênea que se forma em solo mexicano e, que é mister do cenário cultural local desse povo, bem como da América Latina na atualidade.

No entanto, essa sociedade é marcada pelo trauma da "maldición de malinche", que vê, nessa figura histórica, a representação da perdição do povo asteca frente à invasão estrangeira (espanhola) à época da colonização. Tal ruína, que se estenderia até à contemporaneidade por meio da sujeição/aceitação daquilo que é estrangeiro, em detrimento do "local”, como se observa na canção ' $L a$ maldición de Malinche':

[...]hoy en pleno siglo $\mathrm{XX} /$ nos siguen llegando rubios/y les abrimos la casa/y los llamamos amigos/pero si llega cansado/un indio de andar la sierra/lo humillamos y lo vemos/como extraño por su tierra/hipócrita que te muestras/humilde ante el extranjero/pero te vuelves soberbio/con tus hermanos del pueblo/maldición de Malinche/enfermedad del presente/cuando dejaras mi tierra/cuando

\footnotetext{
${ }^{13}$ A "maldição de malinche" reverbera na atualidade mexicana, seja pela negação de aspectos culturais, onde ocorre a não aceitação de influências inerentes ao contato cultural, seja pelo matiz negativo presente no nome Malinche que o torna um verdadeiro xingamento [buscar informações sobre a expressão "hijos de la chingada"].
}

harás libre a mi gente" (OCHOA PALOMARES, 1975).

Onde uma das personagens centrais da dominação recebe a encarnação da culpa pelo processo de conquista por ter se aliado aos conquistadores espanhóis em troca de algumas contas de vidro. A canção enfatiza, ainda, a perpetuação de um padrão de sujeição perante o estrangeiro visto como superior e digno de maior admiração pelo povo mexicano. Maldição que leva à negação da realidade cultural em que os descendentes do período colonial estão imersos, e que é expressa nesse longo fragmento:

Nuestro grito es una expresión de la voluntad mexicana de vivir cerrados al exterior, sí, pero sobre todo, cerrados frente al pasado. En ese grito condenamos nuestro origen y renegamos de nuestro hibridismo. La extraña permanencia de Cortés y de la Malinche en la imaginación y en la sensibilidad de los mexicanos actuales revela que son algo más que figuras históricas: son símbolos de un conflicto secreto, que aún no hemos resuelto. Al repudiar a la Malinche - Eva mexicana, según la representa José Clemente Orozco en su mural de la Escuela Nacional Preparatoria - el mexicano rompe sus ligas con el pasado, reniega de su origen y se adentra solo en la vida histórica.

El mexicano condena en bloque toda su tradición, que es un conjunto de gestos, actitudes y tendencias en el que ya es difícil distinguir lo español de lo indio. Por eso la tesis hispanista, que nos hace descender de Cortés con exclusión de la Malinche, es el patrimonio de unos cuantos extravagantes que ni siquiera son blancos puros. $Y$ otro tanto se puede decir de la propaganda indigenista, que también está sostenida por criollos y mestizos maniáticos, sin que jamás los indios le hayan prestado atención. El mexicano no quiere ser ni indio, ni español. Tampoco quiere descender de ellos. Los niega. Y no se afirma en tanto que mestizo, sino como abstracción: es un hombre. Se vuelve hijo de la nada. Él empieza en sí mismo.

Esta actitud no se manifiesta nada más en nuestra vida diaria, sino en el curso de nuestra historia, que en ciertos momentos ha sido encarnizada por voluntad de desarraigo. Es pasmoso que un país con un pasado tan vivo, profundamente tradicional, atado a sus raíces, rico en antigüedad legendaria si pobre en historia moderna, sólo se conciba como negación de su origen (PAZ, 1998, p. 36).

Corroborando com o autor, é possível afirmar que a sociedade mexicana atual está imersa em um passado que renega. Mais que renegar o seu 
passado, a sociedade mexicana atual nega o diálogo cultural que a constituiu e a torna o que é hoje, isto é, um povo rico culturalmente porque traz as marcas da relação intercultural entre espanhóis e povos précolombianos. Torna-se lastimável que essa "nação" se conceba apenas por meio da negação de sua tradição.

Esse trauma, conflito interno e inerente à grande maioria dos mexicanos, os paralisa perante a necessidade de reconhecer as suas origens. Reconhecimento que vai muito além de aceitar uma descendência mestiça/híbrida, e chega no patamar de compreender que o diálogo cultural é irreversível no México, incapaz de permitir o apagamento do passado, para que estes sujeitos adotem a ideia de filhos sem pais.

A ideia de contato, motivada pela fronteira tornada real pelos espanhóis presentes no território asteca/mexicano, se esvai, mas segue, metaforicamente, na América Latina - México, isso porque, ainda se percebe o diálogo entre as culturas. Nesse contexto, onde o apagamento dos sinais do passado torna-se impossível, o que se tem a fazer é tomar consciência da realidade e buscar elaborar um discurso que seja próprio da América Latina, do México, que, ao invés de negar, exalte a sua natureza intercultural, e que não fique buscando a mera reprodução do outro do qual se origina.

Ao tomarmos Malinche (2006) como objeto de investigação, percebemos a intervenção da língua como mediadora de relações interculturais, ao mesmo tempo em que, ficou evidente, no texto, a contraposição de narrativas e contra-

narrativas acerca do enredo que se estruturava. Tal narrativa, por ser verossímil, acaba por diluir os limites entre aquilo que é "real" e "não-real", instaurando a produção dentro do espaço daquelas situações/contextos que poderiam ter acontecido/"ser verdades". Realidade que acaba por refletir-se nas leituras que são feitas do texto.

Imbuídos dessa certeza, e, das reflexões empreendidas, podemos considerar a obra analisada como uma representante da produção literária latinoamericana, que cada vez mais, assume um lócus de enunciação particular e revelador. Particular porque é próprio das nações situadas na América Latina, e, revelador pelo fato de desmistificar/esclarecer nosso contexto de formação sociocultural e histórico, ademais de "desvendar" como nos vemos e como devemos nos ver. Para fechar, é salutar afirmarmos que existe um discurso da/para a América Latina, e, este está presente em cada registro que temos feito.

\section{Referências}

ARROJO, Rosemary. Tradução, desconstrução e psicanálise. Rio de Janeiro: Imago, 1993.

BHABHA, Homi K. DissemiNação: Tempo, Narrativa e as Margens da Nação Moderna. Trad. Maria Luiza Cyrino Valle. FALE/UFMG, Belo Horizonte: Curso de Pós-Graduação em Letras, 1995.

ESQUIVEL, Laura. Malinche. Tradução de Léo Schlafman. Rio de Janeiro: Ediouro, 2007.

OCHOA, Amparo \& PALOMARES, Gabino. 'La maldición de Malinche'. 1975. Disponível em: <http://lenguaeempalibertad.blogspot.com.br/2010/10/ palomares-gabino-la-maldicion-de.html> Acesso em: 15 de agos. de 2013.

PALERMO, Zulma. "De fronteras, travesías y otras liminalidades. In: COUTINHO, E. F.; BEHAR, L. B. \& RODRIGUES, S.V. (Orgs.). Elogio da lucidez: a comparação literária em âmbito universal; textos em homenagem a Tânia Franco Carvalhal. Porto Alegre: Evangraf, 2004. p. 237-244.

PAZ, Octávio. El laberinto de la soledad. México, DF: Fondo de Cultura Económica, 1998.

SANTIAGO, Silviano. Uma literatura nos trópicos. Rio de Janeiro: Rocco, 2000. p. 7-26.

TODOROV, Tzvetan. A conquista da América: a questão do outro. Tradução de Beatriz PerroneMoisés. 3. ed. São Paulo: Martins Fontes, 2003. 